\title{
DENTAL-IMPLANT RETAINED MANDIBULAR OVERDENTURE: A CASE REPORT
}

\author{
Gupta $R^{1^{*}}$, Singh $R K^{2}$, Basnet $B B^{3}$
}

\section{Affiliation}

1. Assistant Professor, Department of Prosthodontics, M.B. Kedia Dental College and Teaching Hospital

2 Professor, Department of Prosthodontics, B.P. Koirala Institute of Health Sciences, Nepal

3. Assistant Professor, Department of Prosthodontics, B.P. Koirala Institute of Health Sciences

\section{ARTICLE INFO}

Article History

Received : 10 June, 2018

Accepted : 07 August, 2018

Published : 31 August, 2018

(C) Authors retain copyright and grant the journal right of first publication with the work simultaneously licensed under Creative Commons Attribution License CC - BY 4.0 that allows others to share the work with an acknowledgment of the work's authorship and initial publication in this journal.

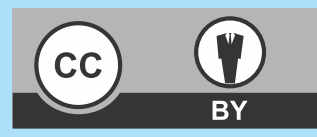

\section{CR 18}

DOI: http://dx.doi.org/10.3126/bjhs.v3i2.20967

\section{* Corresponding Author}

Dr. Rahul Gupta

M.B. Kedia Dental College and Teaching Hospital Nepal Assistant Professor, Department of Prosthodontics Email:drrahul305@gmail.com ORCID: https://orcid.org/0000-0003-2576-2223

\section{Citation}

Gupta R, Singh RK, Basnet BB. Dental-implant Retained Mandibular Overdenture: A Case Report. BJHS 2018;3(2)6:488-491.

\section{ABSTRACT}

The prosthetic management of the patient with resorbed ridge has long been a major challenge for dentistry. Conventional complete denture for long was the standard of care for all such patients. However, most patients find it difficult to adapt to mandibular denture due to lack of retention and stability. Recent scientific studies carried out over the past decade have determined that the benefits of a mandibular two-implant overdenture are sufficient to propose the two-implant overdenture-rather than the conventional denture - as the first treatment option.

\section{KEYWORDS}

Mandible, overdenture, standard of care 


\section{INTRODUCTION}

Ill-formed denture foundation compromises the efforts of an enterprising dedicated clinician to better rehabilitate the masticatory functions. Various proposed conventional method to underpin the efforts in rehabilitation are modifications in impression procedure, neutral zone technique and monoplane occlusion scheme. However, with the advent of Osseo integrated implants, the restorative efforts can now achieve better retention and stability and therefore function more efficiently with better patient acceptability.

\section{CASE REPORT}

A male patient, aged 55 years, presented with a chief complain of missing teeth in the upper and lower jaws. He suffered with no apparent medical illness. On history taking the patient reported to have worn complete dentures for 8 years. Intraoral examination revealed severely resorbed completely edentulous maxillary and mandibular arches with less than optimum foundation for denture bearing and poor prognosis for mandibular denture. The resorption in the mandibular arch was classified as Atwood's orderV (Figure 1).

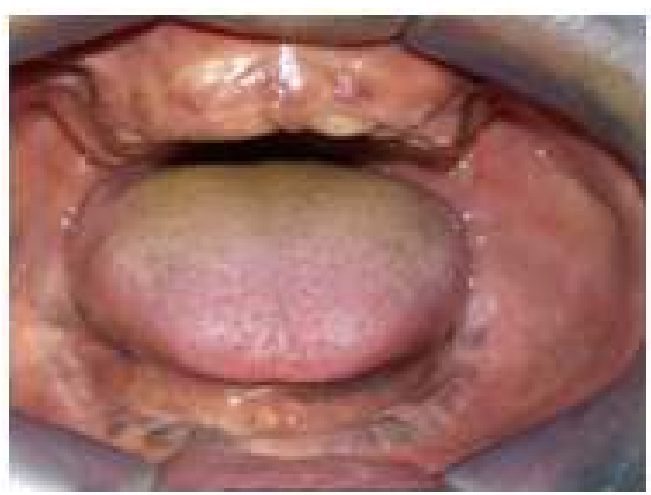

\section{Investigation:}

1. Orthopantomograph with ball bearings (Fig 4.)

2. Bleeding time/Clotting time

3. Blood glucose (Fasting and Post-Prandial)

4. Haemoglobin

5. Calcium

\section{Prosthesis fabrication:}

Maxillary and mandibular preliminary impressions were made in impression compound. Autopolymerising acrylic resin was used to fabricate custom trays. Conventional technique of border moulding and secondary impression were performed for the maxillary arch. Custom tray for the mandibular arch, however, was made according to cock-tail impression technique. The final impression for maxillary arch was made using Zinc oxide eugenol impression paste following the incremental method of border moulding with green stick compound. McCord and Tyson technique using 3:7 parts by weight of impression compound and green tracing stick was used to make the definitive impression for the mandibular arch (Figure 2). Jaw relation, articulation, teeth arrangement and try in (Figure 3.) were done sub sequent to the retrieval of mater casts.

\section{Implant surgery:}

A diagnostic OPG was made after placement of a radiographic stent with two ball bearings followed by bone mapping procedure for the assessment of dimensions of available bone at the proposed site of implant placement.

Figure 1 : Completely edentulous maxillary and mandibular arch
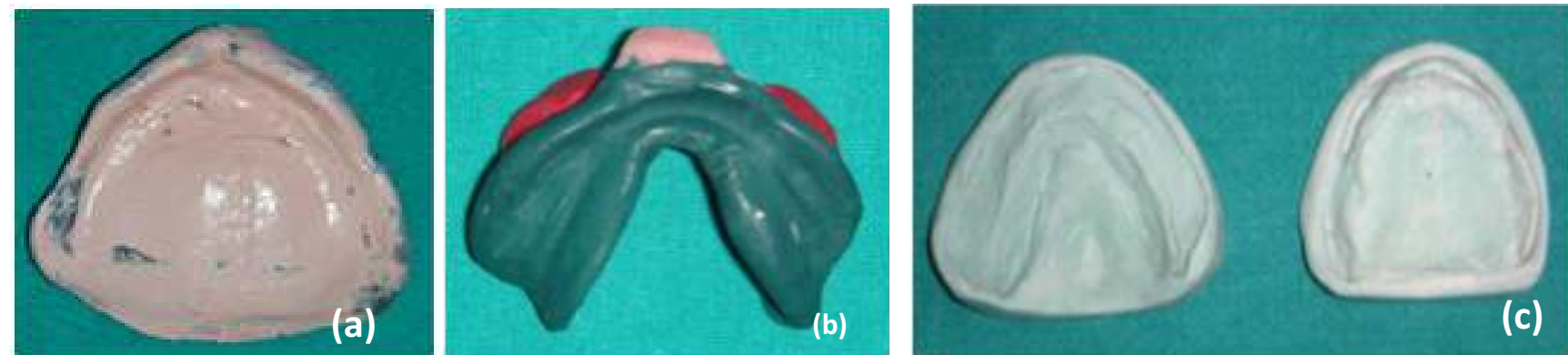

Figure 2: Maxillary final impression following conventional technique (a), Final impression for mandibular arch using Cock-tail impression technique (b), Master Casts (c).
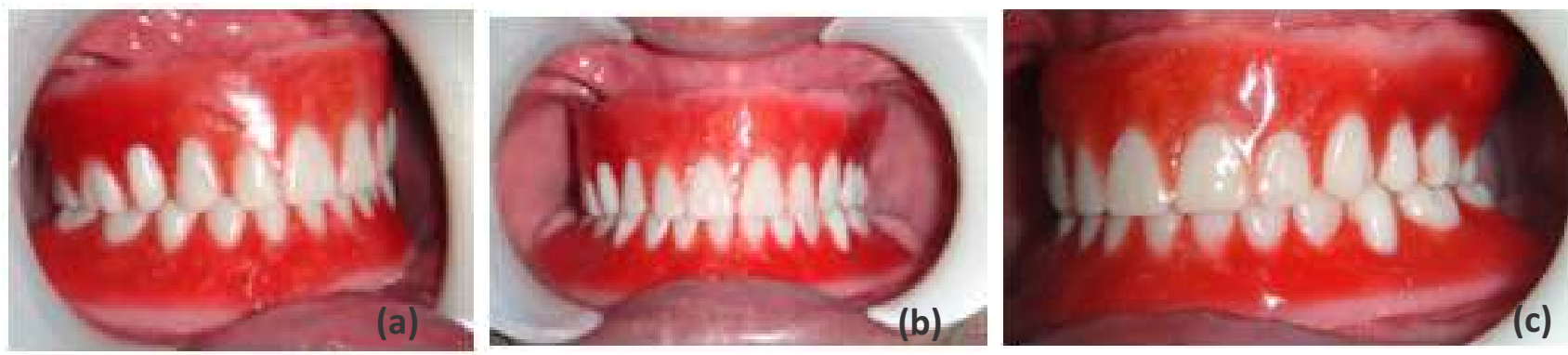

Fig:ire 3: Try in procedure; Right lateral (a), frontal (b), Left lateral (c). 
Potential implant site for overdenture support in anterior mandible between the mental foramens is customarily divided into five equal columns of bone $A, B, C, D$ and $E$ starting from the patient's right side. In our case two stage implant placement protocol was planned and accordingly two implants $3.5 \mathrm{~mm} \times 11.5 \mathrm{~mm}$ were placed in $B$ and $D$ positions (Figure 4) through a crestal incision after one-hour preoperative loading dose of $1000 \mathrm{mg}$ amoxicillin. Interrupted suturing was done using silk 3-0 sutures for primary closure of the line of incision. The patient was then discharged with a prescription of the following

\section{Cap. Amoxicillin 500mg three times daily for three days}

2. Tab. Ibuprofen 400mg three times daily for three days Second stage surgery was performed 3 months postoperative and prefabricated gingival formers were attached, which were subsequently replaced after formation of gingival cuffs with metallic ball abutments. (Figure 5.) compared to maxilla, puts mandibular denture into a compromised position and at bay with retention and stability. ${ }^{2}$ A number of modified impression technique have been described for resorbed mandibular ridges by various authors, such as admixed, functional reline, All-green and cocktail technique conferring better retention and stability to dentures as compared to dentures fabricated by conventional technique. ${ }^{3-7}$ In this case, an analogue for mandibular denture bearing area was obtained using cocktail impression technique and subsequently rehabilitated in accordance to the York consensus statement underpinning two implants supported mandibular overdenture as the first choice of standard of care for mandibular edentulous patients. ${ }^{8}$ Various attachment system have been discussed in scientific literature to connect implants with overdenture. ${ }^{9}$ Yen et.al and Jain et.al have used locator attachment system to connect non-splinted implants with mandibular overdenture. ${ }^{10,11}$ In this case a ball and socket attachment
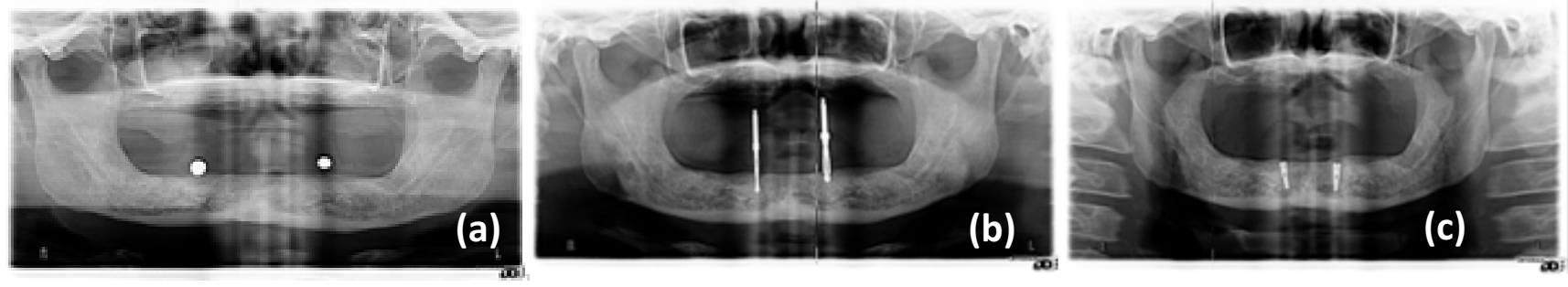

Figure 4. Orthopantomograph with ball bearings in place B and D location, assessment of relative parallelism between performed osteotomy after initial pilot drill (b), after implants insertion (c).
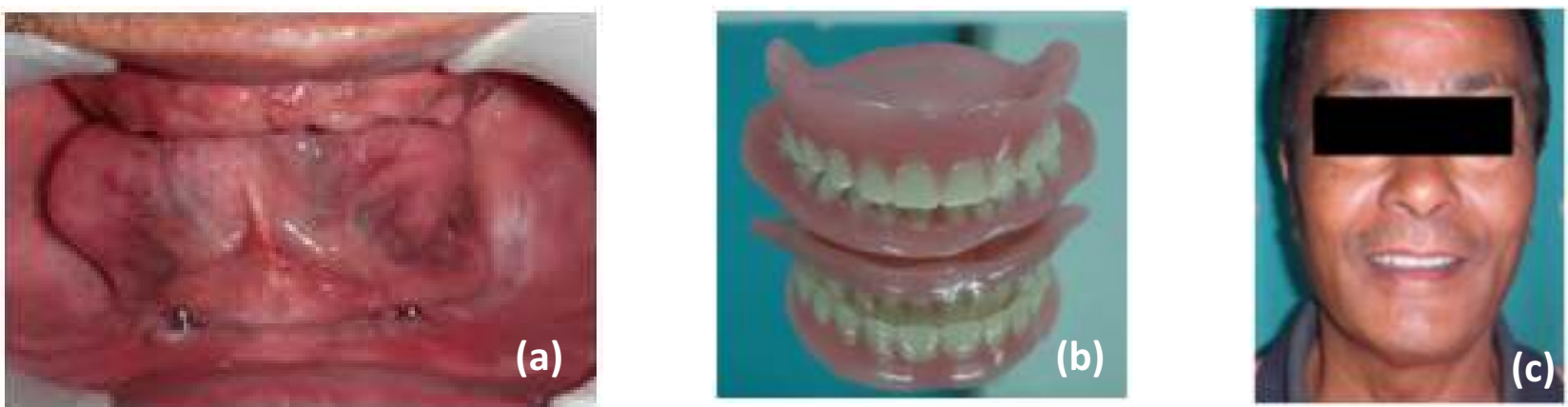

Figure 5: Ball attachment in place (a), Complete denture (b), Rehabilitation with implant supported mandibular overdenture

The abutment site was marked intraorally with an indelible pencil and these markings were transferred to the lower denture. The denture was relieved in the marked area and direct method of attachment of nylon plastic cap with lower denture was used. The fit of the lower denture with nylons caps were evaluated. Patient was recalled after 1 week, 3 weeks, 3 months and 6 months for further evaluation.

\section{DISCUSSION}

A severely resorbed residual ridge is an adverse anatomical presentation for proper functioning of conventional complete dentures. Mandibular edentulous ridge in contrast to maxilla is subject to greater bone resorption, both during the first year of tooth extraction and in the following years. ${ }^{1}$ To add, the disadvantageous ratio of denture bearing area to its circumference for mandible, as was used in OD-1 prosthetic configuration for reasons of financial constraints, better accessibility to oral hygiene procedure and with a recommendation of prosthetic upgradation in subsequent years. The ball attachment used was connected to the overdenture using the direct pick-up procedure instead of the indirect technique for its superior long-term prosthetic aftercare, to curtail the errors in clinical impression and laboratory techniques. ${ }^{12}$ An implant supported overdenture excels conventional complete denture at various fronts viz. retention, stability, chewing efficiency and phonation. ${ }^{13}$ Literature abounds in favourable evidences that support a decline in the rate of bone resorption with use of overdenture as compared to conventional dentures, implying less frequent need for relining and rebasing procedures. ${ }^{14}$ The oral health related quality of life assessment shows a consistently better patient satisfaction and acceptance than with conventional dentures. 


\section{CONCLUSION}

Rehabilitation of the resorbed edentulous mandible is a challenging task. A two-implantsupported over-denture option is a simple, cost effective and minimally cumbersome option for rehabilitation of such patients.

\section{REFERENCES}

1. Zarb GA, Bolender CL. Prosthodontic Treatment for Edentulous Patients: Complete Dentuer and Implant-Supported Prosthesis. 2009. 44-45 p.

2. Roberts AL. Principles of full denture impression making and their application in practise. J Prosthet Dent. 1951;1(3):213-28. PMID: 14832851

3. McCord JF, Tyson KW. A conservative prosthodontic option for the treatment of edentulous patients with atrophic (flat) mandibular ridges. Br Dent J. 1997 Jun;182(12):469-72.PMID: 9231521

4. Winkler S. Essentials of Complete Denture Prosthodontics. 2nd editio. AITBS, New Delhi, India; 2009.

5. Tunkiwala A, Ram S. Management of mandibular poor foundation: conventional complete dentures. Dent Pract. 2013;11(5):34-37. Available from: http://imparteducation.in/downloads1/ Tunkiwala/Management\%20of\%20Mandibular\%20P oor\%20Foun dation.pdf.

6. Praveen G, Gupta S, Agarwal S, Agarwal S. Cocktail impression technique: a new approach to atwood's order VI mandibular ridge deformity. J Indian Prosthodont Soc. 2011;11(1):32-35.DOI: 10.1007/s13191-011-0055-z

7. Yadav B, Jayna M, Yadav H, Suri S, Phogat S, Madan R. Comparison of Different Final Impression Techniques for Management of Resorbed Mandibular Ridge: A Case Report. CaseRepDent [Internet].2014;2014(4):1-6.DOI: 10.1155/2014/253731

8. Thomason J, Feine J, Exley C, Moynihan P, Müller F, Naert I, et al. Mandibular two implant-supported overdentures as the first choice standard of care for edentulous patients--the York Consensus Statement. Br Dent J [Internet]. 2009;207(4):185-6. DOI: 10.1038/ sj.bdj.2009.728

\section{CONFLICT OF INTEREST}

None

\section{FINANCIALDISCLOSURE}

None

9. Alqutaibi AY, Kaddah AF, Ahmed C, Alqutaibi Y. Attachments used with implant supported overdenture. Int Dent Med J Adv Res [Internet]. 2016;2(2):1-5. DOI: 10.15713/ins.idmjar.45

10. Yen $\mathrm{H}$, Chen $\mathrm{M}$, Lin $\mathrm{H}$, Kuo $\mathrm{S}$, Juan $\mathrm{P}$, Liao P. Implant retained overdenture improves the retention and stability by using a Locator $^{\circledast}$ system in a mandibular edentulous patient: A Case Report. J Prosthodont Implantol. 2013;2(2):26-30. Available from: http:// www.prosthod.org.tw/doc/mgzp/2-2/apd_mgz_p2-2-5.pdf

11. Jain $\mathrm{S}$, Gandhi P, Bhatia P. Dental implant retained mandibular overdenture with Locator attachments - A Case Report. IOSR J Dent Med Sci. 2016;15(5):33-5. DOI: 10.9790/0853-1505083335

12. Nissan J, Oz-Ari B, Gross O, Ghelfan O, Chaushu G. Long-term prosthetic aftercare of direct vs. indirect attachment incorporation techniques to mandibular implant-supported overdenture. Clin Oral Implant Res. 2011;22(6):627-30.DOI: 10.1111/j.1600-0501. 2010.02026

13. Mancuso DN, Goiato MC, Gennari Filho H, Gomes erica A. Bite force and masticatory efficiency in implant-retained dentures: Literature review. Dent Today. 2008;27(8):1-6.PMID: 18717400

14. Lopez RA, Abad DS, Bertomeu IG, Castillo EG, Otaolaurruch ES.Bone resorption processes in patients wearing overdentures. A 6-years retrospective study. Med Oral Patol Oral Cir Bucal.2009 Apr;14(4):E203-9: PMID: 19333190 